\title{
A docência na Educação Superior e a constituição da professoralidade
}

\author{
Teaching in Higher Education and the constitution of professorality
}

La docencia en la Educación Superior y la constitucion de la profesoralidad

VERA LUCIA RAMIREZ*

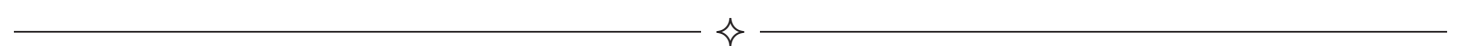

\begin{abstract}
RESUMO
O artigo apresenta reflexões decorrentes de uma pesquisa, tipo estudo de caso, que focalizam a formação continuada em serviço dos docentes universitários que atuam numa universidade comunitária. Fundamenta-se na concepção da constituição da professoralidade como um processo contínuo ao longo da trajetória de vida pessoal-profissional do docente. Defende que a formação continuada deve ser gestada, considerando-se o contexto, os saberes, as demandas formativas e o protagonismo daqueles a quem se destina. Indica a abertura de espaços, tempos e mecanismos que viabilizem aos docentes externalizar suas necessidades e expectativas, e compartilhar conhecimentos e práticas pedagógicas. Aponta para os processos de autoformação e heteroformação como possibilidades para a consolidação de comunidades colaborativas de aprendizagem.

Palavras-chave: Educação superior. Professoralidade. Formação continuada. Autoformação-heteroformação.
\end{abstract}

\begin{abstract}
This paper presents considerations that resulted from a study case research that was focused on continuing education of university professors currently working at a community university. The research is based on the conception of the institution of professorality as a continuous process to be considered along the personal and professional development of professors. This concept states that continuing education has to be nurtured considering the context, the knowledge, the training demands as well as the protagonism of those for whom it is intended. It indicates the opening of spaces, time and mechanisms that enable professors to outsource their needs, expectations as well as to share knowledge and pedagogical practices. It points to self-training processes and hetero-formation as methodologies to allow the consolidation of collaborative learning communities.
\end{abstract}

Keywords: Higher Education. Professorality. Continued formation. Self-formation. Hetero-formation.

\section{RESUMEN}

El artículo presenta reflexiones provenidas de una investigación del tipo estudio de caso, que enfoca la formación continua de docentes universitarios que actúan en una universidad comunitaria. Se fundamenta en la concepción de constitución de la profesoralidad como un proceso continuo a lo largo de la trayectoria de vida personal-profesional del docente. Defiende que la formación continua debe ser gestada, considerándose el contexto, los saberes, las demandas formativas y el protagonismo de aquellos a los que se destina. Indica la apertura de espacios, tiempos y mecanismos que viabilicen a los docentes externalizar sus necesidades, expectativas y compartir conocimientos y prácticas pedagógicas. Señala hacia los procesos de autoformación y de heteroformación como posibilidades para la consolidación de comunidades colaborativas de aprendizaje.

Palabras clave: Educación superior. Profesoralidad. Formación continua. Autoformación-heteroformación.

\footnotetext{
* Doutora em Educação pela Pontifícia Universidade Católica do Rio Grande do Sul. Pós-Doutorado em Educação na Universidade Federal Fluminense (UFF). Professora do Mestrado em Educação da Universidade La Salle de Canoas/RS. Pró-Reitora de Graduação da Universidade La Salle de Canoas/RS.

E-mail:vera.ramirez@unilasalle.edu.br
} 


\section{INTRODUÇÃO}

As Instituições de Ensino Superior, locus privilegiado da (re)construção, da socialização, da difusão dos conhecimentos científicos e da formação profissional, requerem que, especialmente, os docentes que nestas atuam estejam qualificados para o exercício da docência nesse contexto, tendo presente suas complexidades e especificidades. Sem dúvida, não é mais possível se conceber que esse profissional possa ter o mesmo perfil de épocas passadas, em que o domínio de um conjunto de conhecimentos e de determinadas técnicas era o suficiente para exercer o ofício de professor.

Assim, ao se discutir o exercício da docência, é preciso se ter presente aspectos tais como os processos de constituição profissional; os saberes mobilizados nas práticas educativas, as questões atinentes à pedagogia universitária e à formação continuada desse profissional (CUNHA, 1998; MASETTO, 2003; ISAIA; BOLZAN, 2008; IMBERNÓN, 2009; BOLZAN; ISAIA, 2010).

Esse conjunto de aspectos transversalizam o desenvolvimento profissional dos professores e estão sujeitos a influências e pressões por parte de variadas instâncias, sejam elas oficiais, extraoficiais, profissionais e extraprofissionais. Dessa forma, as concepções e práticas de formação, seja ela inicial ou continuada, estão relacionadas a uma base epistemológica e pedagógica, que variam de acordo com cada contexto sociocultural, histórico e educacional.

Diante disso, esforços têm sido empreendidos com o intuito de desvelar as possibilidades de potencializar o protagonismo docente nos processos de autoformação e heteroformação, com vistas à consolidação de comunidades colaborativas de aprendizagem no contexto de uma universidade comunitária.

Parte-se do pressuposto de que a formação continuada em serviço é uma das dimensões fundamentais no processo de constituição daquilo que vem sendo denominado como professoralidade (ISAIA; BOLZAN, 2008; BOLZAN; ISAIA, 2010). Segundo Isaia e Bolzan (2008, p. 110), esta é compreendida como:

Um processo que implica não só o domínio de conhecimentos, de saberes, de fazeres de determinado campo, mas também a sensibilidade do docente como pessoa e profissional em termos de atitudes e valores, tendo a reflexão como componente intrínseco ao processo de ensinar, de aprender, de formar-se e, consequentemente, de desenhar sua própria trajetória.

Na constituição da professoralidade, o protagonismo é fundamental, pois o docente necessita estar engajado e assumir o compromisso com a sua própria formação. Entretanto, o exercício da docência ocorre num cenário pautado por um projeto coletivo de educação, mesmo que este esteja somente no plano instituído, no qual várias vozes, concepções, saberes e fazeres estão em cena numa trama de relações. Portanto, a formação se efetiva nos âmbitos da autoformação e da heteroformação. Corrobora-se a posição de Bolzan e Isaia (2010, p. 16), quando as autoras afirmam que:

A construção da aprendizagem de ser professor, portanto, é colaborativa, faz-se na prática de sala de aula e no exercício de atuação cotidiana da universidade. É uma conquista social, compartilhada, que envolve trocas e representações. Com essa postura, o professor está produzindo sua professoralidade, o que implica não só em dominar conhecimentos, saberes, fazeres de determinado campo, mas também na sensibilidade em termos de atitudes e valores que levem em conta os saberes da experiência. Esta, contudo, precisa ser entendida a partir de uma ótica de reflexão sistemática na qual o foco está nas relações interpessoais, componente intrínseco ao processo de ensinar, aprender, formar-se e, consequentemente, desenvolver-se profissionalmente.

Realizadas tais considerações, o artigo apresenta reflexões decorrentes de uma pesquisa, tipo estudo de caso, que focaliza a formação continuada em serviço dos docentes universitários que atuam numa universidade comunitária. Dessa forma, em termos de estrutura, inicialmente introduz-se a temática analítica. A seguir, descreve-se a abordagem metodológica adotada para o desenvolvimento do estudo. Na sequência, compartilhamse aspectos atinentes à análise e à interpretação dos dados coletados. Por fim, retomam-se os pressupostos centrais abordados em termos de considerações finais.

\section{ABORDAGEM METOdológicA}

A pesquisa, do tipo estudo de caso, focaliza a formação continuada em serviço dos docentes que atuam numa universidade comunitária, problematizando as possibilidades de potencializar o protagonismo docente nos processos de autoformação e heteroformação, com vistas à consolidação de comunidades colaborativas de aprendizagem nesse contexto educativo.

De acordo com Yin (2005, p. 20), "utiliza-se o Estudo de Caso em muitas situações, para contribuir com o conhecimento que temos dos fenômenos individuais, organizacionais, sociais, políticos e de grupo, além de outros fenômenos relacionados". O autor explica que essa abordagem investigativa

[...] permite uma investigação para se preservar as características holísticas e significativas dos acontecimentos da vida real - tais como ciclos 
de vida individuais, processos organizacionais e administrativos, mudanças ocorridas em regiões urbanas, relações internacionais e a maturação de setores econômicos.

A unidade de estudo é a Universidade La Salle, a qual tem por missão "promover a formação integral e continuada da pessoa por meio do ensino, da pesquisa e da extensão, para o desenvolvimento sustentável da sociedade, com base nos princípios cristão-lassalistas" (CENTRO UNIVERSITÁRIO LA SALLE, 2016b, p. 14). Essa missão se concretiza por meio da ação educativa, desenvolvida em conformidade com o Plano de Desenvolvimento Institucional (PDI), políticas, diretrizes, objetivos e orientações presentes no Projeto Pedagógico Institucional (PPI) e nos Projetos Pedagógicos dos Cursos (PPCs).

Participam do estudo 215 docentes que atuam nos cursos de graduação (bacharelado, tecnólogos e licenciaturas) da universidade, os quais participam de ações de formação continuada em serviço promovidas no decorrer do ano letivo pela instituição. Tais ações estão previstas nos objetivos estratégicos constantes no Plano de Desenvolvimento Institucional (PDI) da universidade, pois esta prima e favorece a formação dos professores que atuam nos cursos oferecidos, sendo a educação continuada um dos princípios filosóficos e técnico-metodológicos que fundamentam sua ação institucional (CENTRO UNIVERSITÁRIO LA SALLE, 2016b, p. 8-9).

O Núcleo de Apoio Pedagógico (NAP) é a instância responsável pelo planejamento e pela efetivação do Programa de Formação Continuada dos Docentes. Está composto por docentes representantes das áreas de conhecimento dos 40 cursos de graduação ofertados.

Semestralmente, o Núcleo de Apoio Pedagógico (NAP) discute e propõe diversos espaços formativos para os professores que lecionam no ensino superior (seminários, palestras, mesas temáticas, minicursos). Tais ações formativas abordam temáticas de interesse do corpo docente, com o intuito de contribuir para o aprimoramento da gestão educacional, para a melhoria dos processos de ensino-aprendizagem, para o fortalecimento das relações interpessoais, para a promoção de um clima de bem-estar e para a vivência dos valores cristãos.

A opção por uma política de formação continuada para os docentes universitários consolida a qualificação na perspectiva da melhoria expressiva da qualidade do ensino superior. De certa forma, a ausência ou a precariedade de uma formação didático-pedagógica pode trazer implicações para o exercício da docência, considerando que não basta o professor ser habilitado para os conteúdos específicos. Ou seja, é necessário que o professor tenha domínio também de um conjunto de saberes, procedimentos e técnicas que the viabilizem explorar e trabalhar os conteúdos de forma didática, favorecendo o processo de aprendizagem. A Declaração Mundial sobre Educação Superior no Século XXI (UNESCO, 1998) reforça que:

\begin{abstract}
Devem ser tomadas providências adequadas para pesquisar, atualizar e melhorar as habilidades pedagógicas, por meio de programas apropriados de desenvolvimento de pessoal, estimulando a inovação constante dos currículos e dos métodos de ensino e aprendizagem, que assegurem as condições profissionais e financeiras apropriadas ao profissional, garantindo assim a excelência em pesquisa e ensino, de acordo com as provisões da Recomendação referente ao Estado do Pessoal Docente da Educação Superior aprovado pela Conferência Geral da UNESCO em novembro de 1997.
\end{abstract}

Partindo desse contexto, é preciso refletir sobre o preparo efetivo do corpo docente, principalmente daqueles que nunca tiveram contato com uma formação pedagógica que propiciasse o desenvolvimento profissional, interligando competência técnica com competência pedagógica. Contudo, é preciso ter presente as reais demandas formativas dos professores para não incorrer num erro muito frequente de propostas formativas desvinculadas de suas reais necessidades docentes, conforme alertam autores, tais como Bélair (2001) e Nóvoa (2008). Nesse sentido, conforme destaca Bélair (2001, p. 64), a formação

[...] não pode ser percebida como uma lista de aquisições lineares, cuja soma equivale ao todo. Pelo fato de compreender um conjunto de tarefas complexas e exigir saberes experimentais, esse ofício é ensinado mais do que tudo em uma relação com essa complexidade e na organização personalizada de aprendizados nessa rede de tarefas; trata-se de valorizar as atitudes que dão conta da globalidade do ofício de ensinar, mais do que a soma descorticada de competências múltiplas.

Nessa linha reflexiva, Nóvoa (2008, p. 11) assevera que:

Grande parte dos programas de formação contínua tem-se revelado de grande inutilidade, servindo apenas para complicar um quotidiano docente já de si fortemente exigente. Os professores devem recusar o consumismo de cursos, seminários e acções que caracteriza o "mercado da formação" e que alimenta um sentimento de "desactualização" dos professores. A concepção da Educação Permanente obriga-nos a pensar ao contrário, construindo os dispositivos de formação a partir das necessidades das pessoas 
e da profissão, investindo na construção de redes de trabalho colectivo que sejam o suporte de práticas de formação baseadas na partilha e no diálogo profissional (grifo do autor).

Dessa forma, tendo em vista a problemática investigativa do estudo, para a coleta de dados recorre-se à análise documental do PDI e dos Relatórios do NAP atinentes ao ciclo formativo no espaço temporal dos dois últimos anos. Busca-se, nesses documentos, mapear os modos constitutivos das propostas formativas em termos de identificação das demandas docentes, as escolhas das tipologias das ações a serem desenvolvidas e os registros das avaliações dos docentes participantes.

Ao utilizar como corpus investigativo esses documentos, partilha-se a compreensão de Flick (2009, p. 232) quando o autor ressalta que: "Ao decidir-se pela utilização de documentos em um estudo, deve-se sempre vê-los como meios de comunicação". O autor continua explicando que:

O pesquisador deverá também perguntar-se acerca de: quem produziu esse documento, com que objetivo e para quem? Quais eram as intenções pessoais ou institucionais com a produção e o provimento desse documento ou dessa espécie de documento? Os documentos não são, portanto, apenas simples dados que se pode usar como recurso para a pesquisa. Uma vez que comece a utilizá-los para a pesquisa, ao mesmo tempo o pesquisador deve sempre focalizar esses documentos enquanto um tópico de pesquisa: quais são suas características, em que condições específicas foram produzidos, e assim por diante (FLICK, 2009, p. 232-233).

Com base na Técnica de Análise de Conteúdo, proposta por Bardin (2011), organizam-se os dados no eixo temático o qual se denomina protagonismo docente na autoformação e heteroformação: em busca da consolidação de comunidades colaborativas de aprendizagem, cuja reflexão é foco da seção apresentada na sequência.

\section{O PROTAGONISMO DOCENTE NA AUTOFORMAÇÃO E HETEROFORMAÇÃO: EM BUSCA DA CONSOLIDAÇÃO DE COMUNIDADES COLABORATIVAS DE APRENDIZAGEM}

A reflexão sobre a docência no ensino superior levanta a discussão acerca da formação docente e das condições pelas quais esses profissionais atuam no contexto acadêmico. Essa formação precisa ser instrumentalizada de tal forma que eles "[...] compreendam os contextos históricos, sociais, culturais, organizacionais nos quais se dá sua atividade docente, como condição de nela intervir" (PIMENTA; ANASTASIOU, 2002, p. 24).

Mizukami (1996) sinaliza para a amplitude do processo constante e permanente para aprender a ser professor. Para ela, várias dessas aprendizagens vão ocorrer, na maioria das vezes, no fazer pedagógico cotidiano. Portanto, conforme a autora, é fundamental conhecer o professor e o seu modo de ser professor, pois ele:

[...] é o principal mediador entre os conhecimentos socialmente construídos e os alunos. É ele, igualmente, fonte de modelos, crenças, valores, conceitos e préconceitos, atitudes que constituem, ao lado do conteúdo específico da disciplina ensinada, outros tipos de conteúdos por ele mediados. Conhecer quem é esse profissional, sua trajetória escolar, sua formação básica, como ele se desenvolve ao longo de sua trajetória profissional é, sob essa perspectiva, de fundamental importância quando se pensa em oferecer um ensino de qualidade [...] (MIZUKAMI, 1996, p. 60).

Assim, a formação:

[...] deveria apoiar-se, criar cenários e potencializar uma reflexão real dos sujeitos sobre a sua prática docente nos centros e nos territórios, de modo que lhes permita examinar suas teorias implícitas, seus esquemas de funcionamento, suas atitudes etc., potencializando um processo constante de autoavaliação do que se faz e analisando o porquê se faz (IMBERNÓN, 2009, p. 47).

Schön (1992), ao propor a ideia do prático reflexivo, sugere que a formação precisa contemplar o conhecimento na prática, pela reflexão da prática e pela reflexão sobre a reflexão sobre a prática. Nessa mesma linha reflexiva, Charlier (2001, p. 93), destaca a importância de se ter presente que:

O professor pode aprender a partir da prática na medida em que esta constitui o ponto de partida e o suporte de sua reflexão (reflexão sobre a ação), seja sua própria prática ou a de seus colegas (aprendizado ocasional). O professor aprende através da prática. Confrontando a realidade que resiste a ele, o professor coloca-se como ator, isto é, como qualquer um pode interferir nas características da situação, experimentar condutas novas e descobrir soluções adequadas à situação. O professor aprende para a prática, pois, se o ponto de partida do aprendizado está na ação, seu desfecho também está, em que o professor valoriza essencialmente os aprendizados que para ele têm incidência direta sobre a sua vida.

Por isso, quando se fala em formação, tem-se presente que esta contempla tanto os conhecimentos e os 
procedimentos específicos da profissão quanto dimensões relativas ao desenvolvimento pessoal. Parece já ser consenso, no campo da educação, a impossibilidade de separar o "eu profissional do eu pessoal" (NÓVOA, 2000; ISAIA, 2001), pois "o conjunto de valores e crenças que dão escopo à performance dos docentes são fruto de sua história e suas experiências de vida, que dão contornos ao seu desempenho" (CUNHA, 1998, p. 53).

O desenvolvimento pessoal, visto a partir de uma perspectiva da integralidade da pessoa do professor, resgata a dicotomia e rompe, de certo modo, com esta entre as dimensões pessoal e profissional. Ou seja, o docente não se constitui meramente com conhecimentos teóricos e metodológicos, mas também nesse processo constitutivo os conteúdos que viabilizam e promovem uma formação pessoal são essenciais (ABRAHAM, 2000; ARCHANGELO, 2004; ISAIA, 2001; NÓVOA, 1999, 2000). No dizer de Archangelo (2004, p. 11-12), os professores, enquanto pessoas, são seres:

[...] dotados de afetividade, dotados de uma forma específica de enfrentar desafios e adversidades, de uma certa capacidade de compreensão, de elaboração, um certo envolvimento com as questões da profissão e da vida. Tais mecanismos sofrem a resistência de um ser que interage, que constrói um sentido para as situações vividas, transformando-se e transformando-as.

Para Mizukami (1996, p. 60), é fundamental conhecer o professor e o seu modo de ser professor, pois ele:

[...] é o principal mediador entre os conhecimentos socialmente construídos e os alunos. É ele, igualmente, fonte de modelos, crenças, valores, conceitos e préconceitos, atitudes que constituem, ao lado do conteúdo específico da disciplina ensinada, outros tipos de conteúdos por ele mediados. Conhecer quem é esse profissional, sua trajetória escolar, sua formação básica, como ele se desenvolve ao longo de sua trajetória profissional é, sob essa perspectiva, de fundamental importância quando se pensa em oferecer um ensino de qualidade [...].

O docente, enquanto um ator social, faz parte de uma coletividade juntamente com outros profissionais que "são diferentes entre si, e carregam para esse espaço de interação tais diferenças" (ARCHANGELO, 2004, p. 12). Portanto, no contexto universitário, "convergem os diferentes interesses profissionais, as habilidades individuais, os posicionamentos políticos, entre tantas outras diferenças" (ARCHANGELO, 2004, p. 12). A convivência com essa diversidade produz efeitos no ser pessoal e profissional do docente, requerendo dele uma adaptação e interação nesse contexto profissional. Desse ponto de vista, conforme asseveram
Pimenta e Anastasiou (2002, p. 259), "o processo de docência e do desenvolvimento profissional, mediante a preparação pedagógica, não se dará em separado de processos de desenvolvimento pessoal e institucional".

A análise dos Relatórios do NAP atinentes ao Programa de Formação Continuada dos Docentes, nos últimos dois anos, possibilita visualizar o crescente esforço empreendido em prol da qualificação permanente dos docentes que atuam na universidade. Nos registros constantes dos relatórios, fica evidenciado que os docentes apontam a dinâmica da formação continuada como fator essencial na qualificação de suas práticas e do desenvolvimento de seu trabalho educativo. Nos diagnósticos realizados pelo NAP, os professores indicam temáticas a serem trabalhadas nas modalidades formativas ofertadas, dentre as quais se sobressaem aquelas relativas às questões de cunho metodológico e às atinentes à avaliação da aprendizagem.

No que se refere às questões de cunho metodológico, há um acento na possibilidade de desenvolver projetos interdisciplinares e em dinâmicas diferenciadas que permitam abordar os conteúdos, visando a uma maior mobilização dos acadêmicos em termos de interesse, participação e corresponsabilidade com sua aprendizagem. Concorda-se com Altet (2001, p. 26) que "ensinar é fazer aprender e, sem a sua finalidade de aprendizagem, o ensino não existe [...] o professor é um profissional da aprendizagem, da gestão de condições de aprendizagem e da regulação interativa em sala de aula".

Em relação ao processo de ensino, há consenso que não é mais possível conceber o professor como mero transmissor de conhecimentos. Dessa forma, a abordagem metodológica adotada na educação superior precisa ter como eixo condutor a problematização, a reflexão, o desenvolvimento do espírito crítico e investigativo, dentre outros.

As situações problemáticas que os professores enfrentam no dia a dia, na maioria das vezes, estão relacionadas à sua formação estritamente técnica. Por isso, a importância de a instituição intensificar as ações de formação continuada de seus docentes. Dificuldades e limitações devem ser encaradas como desafio para o aperfeiçoamento do desempenho pedagógico do docente universitário, superando o distanciamento entre formação técnica e pedagógica.

A corresponsabilidade nos processos de ensino e aprendizagem é outro fator a ser discutido. Com base na ideia do aluno como construtor e protagonista de sua formação, a autonomia cognitiva discente é um objetivo a ser perseguido na educação superior. Assim, no entender de Masetto (2003, p. 23): 
[...] se entendemos que, no ensino superior, a ênfase deva ser dada às ações do aluno para que ele possa aprender o que se propõe; que a aprendizagem desejada engloba, além dos conhecimentos necessários, habilidades, competências e análise e desenvolvimento de valores, não há como se promover essa aprendizagem sem a participação e parceria dos próprios aprendizes. Aliás, só eles poderão "aprender".

Ainda, conforme Felicetti e Morosini (2010, p. 14-15),

[...] o comprometimento do estudante com sua aprendizagem se refere a como se faz, com o que se faz e com que intensidade se faz toda atividade que possa vir a contribuir para uma melhor aprendizagem e, consequentemente, melhor qualidade na formação acadêmica. [...] os altos índices de engajamento/ comprometimento estudantil são associados a um conjunto de práticas e condições educacionais, tais como o contato entre professor-aluno, as aprendizagens colaborativas e ativas, a percepção do aluno quanto ao ambiente universitário, a satisfação, a persistência, a realização educacional, entre outras. [...] O engajamento/ comprometimento do aluno em atividades universitárias, seja dentro ou fora da sala de aula, é visto como uma possibilidade de sucesso no meio universitário, proporcionando o desenvolvimento do discente em inúmeras áreas e também o estimulando a persistir na universidade.

Com relação à avaliação da aprendizagem, a preocupação está na construção de instrumentos que permitam analisar o desempenho dos acadêmicos de forma mais efetiva. Os conhecimentos necessários para a aprendizagem do aluno, as habilidades e competências e o desenvolvimento de valores trazem implicações para o perfil do professor que exerce à docência no ensino superior, ou seja, incidem sobre "as competências básicas e necessárias para se realizar a docência" (MASETTO, 2003, p. 25).

Em termos gerais, Masetto refere-se às seguintes competências básicas para a docência: conhecimentos e práticas profissionais atualizadas; produção científica decorrente de estudos e reflexões críticas sobre temas teóricos ou experiências pessoais; domínio na área pedagógica, contemplando saberes atinentes ao processo de ensino-aprendizagem, à gestão do currículo, à compreensão sobre a relação professor-aluno e teoria e prática da tecnologia educacional e ao exercício da dimensão política.

As ações formativas conduzidas com a mediação dos próprios pares, especialmente aquelas que viabilizam a partilha de experiências e saberes nas áreas de atuação dos docentes, recebem destaque nas avaliações realizadas constantes nos registros dos relatórios. Tal constatação remete à posição de Cunha (1998, p. 35), quando a autora ressalta

[...] o valor que os professores dão à prática docente enquanto a sua grande inspiração para a mudança $\mathrm{e}$ ao saber que constroem a partir daí. Nela localizam a possibilidade de aprenderem com colegas de trabalho, com alunos e de, refletindo sobre a própria docência, reformularem sua forma de pensar e de agir.

Fica evidenciado também, nos registros, que as relações interpessoais que o docente estabelece com seus pares podem ser elementos facilitadores ou inibidores de seu desenvolvimento pessoal-profissional. Um ambiente de trabalho em que os docentes são respeitados em seu saber e continuamente desafiados contribuirá, provavelmente, para que tais profissionais possuam uma atitude proativa nas questões relativas à sua atuação pedagógica.

O desenvolvimento de projetos interdisciplinares, contemplando um conjunto de componentes curriculares dentro do curso e entre cursos é destacado pelos docentes. Contudo, no entender deles, aqui se tem um ponto crítico, pois os espaços e tempos remunerados para que seja viável um planejamento em conjunto, a fim de se concretizar o ideário de um currículo interdisciplinar pautado pelo desenvolvimento de competências, ainda são insuficientes. Isso remete à reflexão sobre o regime de trabalho dos docentes, pois nem todos estão inseridos no regime de tempo integral.

Igualmente, a concretização da tríplice missão universitária do ensino, da pesquisa e da extensão no decorrer do itinerário formativo dos acadêmicos, fica por vezes prejudicada devido às limitações, em termos de investimentos, em projetos de pesquisa e de extensão, tanto por parte da própria universidade quanto por agências e órgãos de fomento. A articulação entre ensino, pesquisa e extensão pressupõe que os estudantes sejam mobilizados

[...] a produzir, aplicar e disseminar conhecimento científico, cultural, social e tecnológico, consolidando a relação entre Extensão e Pesquisa, favorecendo a criação e recriação de conhecimentos que podem contribuir na relação entre a universidade e a sociedade para transformação social, para o desenvolvimento teórico, bem como para retroalimentar parte da ação pedagógica da universidade (CENTRO UNIVERSITẢRIO LA SALLE, 2016c, p. 8).

A sociedade contemporânea requer um perfil de egresso da educação superior com competências e habilidades que lhe viabilizem agir e tomar decisões numa sociedade cuja característica principal é a constante 
transformação. Para tanto, a pesquisa é fundamental para os processos de produção, divulgação e socialização do conhecimento. Investir em pesquisa significa oferecer, além de recursos materiais e físicos, horas remuneradas para que o professor se dedique a tal ação. Contudo, na atual conjuntura econômica, a dificuldade em termos de sustentabilidade econômico-financeira inviabiliza muitas Instituições de Ensino Superior (IESs) de manter um corpo de pesquisadores em nível de graduação. As que oferecem cursos de pós-graduação stricto sensu têm focalizado os investimentos em pesquisa nesse nível de ensino.

A partir dos registros analisados nos relatórios, pode-se afirmar a importância da formação continuada em serviço para a constituição da professoralidade, pois esses espaços propiciam um aprendizado contínuo em que o movimento dinâmico e constante da teoria com a prática e da prática com a teoria proporciona a (re)construção de saberes e fazeres pedagógicos.

\section{CONSIDERAÇÕES FINAIS}

O docente universitário necessita estar em constante formação, pois a sua professoralidade se constitui por meio de um processo contínuo ao longo de sua trajetória. Desse modo, a formação continuada é um elemento essencial a ser gestado, considerando o contexto, os saberes, as demandas formativas e o protagonismo daqueles a quem se destina.

Nessa perspectiva, pode-se reforçar a posição de Nóvoa (2009, p. 34) ao reforçar "a necessidade de devolver a formação de professores aos professores", pois, segundo ele, "os processos de formação só fazem sentido se eles forem construídos dentro da profissão".

Para que isso se materialize, é fundamental que as Instituições de Ensino Superior, quando se trata da formação continuada em serviço, promovam a abertura de espaços, tempos e mecanismos que viabilizem aos docentes externalizar suas necessidades, expectativas e também compartilhar conhecimentos e práticas pedagógicas.

A formação somente será efetivada no que se refere aos seus objetivos se o docente se assumir como protagonista nos processos de autoformação e heteroformação. Ou seja, protagonizar o seu próprio processo formativo, contribuindo por meio da reflexão, da partilha e da construção coletiva para a formação do outro, como possibilidade para a consolidação de comunidades colaborativas de aprendizagem. Nessa perspectiva, rompe-se com a ideia do docente como mero consumidor de formação, cuja proposição por vezes é gestada por outros profissionais que se pautam em possíveis suposições sobre as demandas formativas dos docentes.
Entende-se que aqui reside um dos desafios: mobilizar os docentes para que assumam essa corresponsabilidade, desafiando-se e disponibilizando-se a fazer parte de um coletivo que reflete, aprofunda, discute e (re)inventa seu fazer cotidiano. Essa mobilização e abertura, por vezes, requer uma mudança de concepções, de atitudes e práticas que podem ter se cristalizado ao longo da trajetória docente e, portanto, nem sempre os professores estão dispostos a rever. Diante disso, a própria proposta formativa deve ter presente esse fator, buscando contemplar estratégias que viabilizem lidar com possíveis resistências que possam comprometer uma construção individual e coletiva.

Santos, Antunes e Schmitt (2010, p. 22) dizem que "na relação dialógica entre aprendizagem e ensino, a desmotivação, a falta de entusiasmo, a carência de curiosidade ou a perda de vontade para ensinar-aprender representam um risco de fracasso e remetem à baixa qualidade no ensino superior". Concluem os autores:

[...] a formação continuada proporcionada pelos espaços de autoconhecimento e de trabalho cooperativo pode ser uma maneira de contribuir significativamente para elevar a motivação e promover o bem-estar do professor, consequentemente, desenvolvendo espaços acadêmicos produtivos e orientados para o aprender a aprender.

Tendo presente que as reflexões apresentadas no decorrer deste texto são oriundas de um estudo de caso, e que, conforme Triviños (2008, p. 111), nessa tipologia de investigação "os resultados são válidos só para o caso que se estuda, não se pode generalizar o resultado atingido". Considera-se fundamental retomar a posição de André (1984, p. 52-53), quando a autora refere que:

\footnotetext{
O estudo de caso valoriza o conhecimento experiencial e enfatiza o papel importante do leitor na geração desse conhecimento. É o leitor que deve perguntar a si mesmo: $\mathrm{O}$ que existe neste estudo que eu posso aplicar à minha situação? E, ao fazer as associações e dissociações, o leitor vai construindo as suas próprias interpretações, vai desenvolvendo o seu processo de compreensão das coisas, da realidade, do mundo. É essencial então que o retrato vivo e completo produzido pelo estudo de caso apresente todos os elementos necessários para que o leitor possa fazer as suas interpretações, reiterando ou não, as representações do autor.
}

Por fim, tendo presente o estudo realizado, tem-se ciência da complexidade do ser humano e das próprias instituições e afirma-se que, para as mudanças ocorrerem, é preciso considerar e respeitar os tempos das pessoas, dos grupos e das instituições. 


\section{REFERÊNCIAS}

ABRAHAM, Ada. El universo profesional del enseñante. In: ABRAHAM, Ada et al. El enseñante es también una persona. Barcelona: Gedisa, 2000, p. 21-29.

ALTET, Marguerite. As competências do professor profissional: entre conhecimentos, esquemas de ação e adaptação, saber analisar. In: PAQUAY; Léopold (Org.). Formando professores profissionais. Quais estratégias? Quais competências? Porto Alegre: Artmed, 2001. p. 23-35.

ANDRÉ, Marli E. D. Estudo de caso: seu potencial na educação. Cadernos de Pesquisa, São Paulo, n. 49, p. 51- 54, maio 1984.

BARDIN, Laurence. Análise de conteúdo. Lisboa: Edições 70, 2011

BÉLAIR, Louise. A formação para a complexidade do ofício de professor. In: PAQUAY; Léopold (Org.). Formando professores profissionais. Quais estratégias? Quais competências? Porto Alegre: Artmed, 2001. p. 55-65.

BOLZAN, Doris P.V.; ISAIA, Silvia M. A. Aprendizagem docente na educação superior: construções e tessituras da professoralidade. Educação, Porto Alegre, ano XXIX, v. 60, n. 3, p. 489-501, set./dez. 2006.

BOLZAN, Doris P.V.; ISAIA, Silvia M. A. Pedagogia universitária e aprendizagem docente: relações e novos sentidos da professoralidade. Revista Diálogo Educacional, Curitiba, v. 10, n. 29, p. 13-26, jan./abr. 2010.

CENTRO UNIVERSITÁRIO LA SALLE. Núcleo de Apoio Pedagógico (NAP). Relatório do Programa de Formação Continuada. Canoas, 2015.

CENTRO UNIVERSITÁRIO LA SALLE. Núcleo de Apoio Pedagógico (NAP). Relatório do Programa de Formação Continuada. Canoas, 2016a.

CENTRO UNIVERSITÁRIO LA SALLE (UNILASALLE). Plano de Desenvolvimento Institucional (PDI): 2016-2020. Canoas, 2016b.

CENTRO UNIVERSITÁRIO LA SALLE (UNILASALLE). Políticas de ensino do Unilasalle Canoas: Resolução do Conselho Superior Universitário no 710/2016, de 23 de setembro de 2016. Canoas, 2016c.

CUNHA, Maria Isabel. O professor universitário na transição de paradigmas. Araraquera, São Paulo: JM, 1998.

FELICETTI, Vera Lúcia; MOROSINI, Marília Costa. Comprometimento e pedagogia universitária. In: SANTOS, Betina Steren dos; CARREÑO, Ángel Boza. (Org.). A motivação em diferentes cenários. Porto Alegre: EDIPUCRS, 2010. p. 11-20.

FLICK, Uwe. Desenho da pesquisa qualitativa. Porto Alegre: Bookman, Artmed, 2009.

IMBERNÓN, Francisco. Formação permanente do professorado: novas tendências. São Paulo: Cortez, 2009.

ISAIA, Silvia M. A.; BOLZAN, Doris P. V. Compreendendo os movimentos construtivos da docência superior: construções sobre pedagogia universitária. Linhas Críticas. Brasília, v. 14, n. 26, p. 25-42, jan./jun. 2008.

ISAIA, Silvia M. Professor universitário no contexto de suas trajetórias como pessoa e profissional. In: MOROSINI, M. (Org.). Professor do ensino superior: identidade, docência e formação. 2. ed. Brasília: Plano, 2001. p. 35-60.

MASETTO, Marcos T. Competência pedagógica do professor universitário. São Paulo: Summus, 2003.

MIZUKAMI, Maria da Graça N. Docência, trajetórias pessoais e desenvolvimento profissional. In: REALI, Aline M. M. R.; MIZUKAMI, Maria da Graça N. Formação de professores: tendências atuais. São Carlos: Edufscar, 1996. p. 59-92.

NÓVOA, António. Os professores e o "novo" espaço público da educação. In: TARDIF, Maurice; LESSARD, Claude. (Org.). $\mathrm{O}$ ofício de professor: história, perspectivas e desafios internacionais. Petrópolis, RJ: Vozes, 2008.

NÓVOA, António. O passado e o presente dos professores. In: NÓVOA, António (Org.). Profissão professor. Porto: Porto, 1999. p. 13-21.

NÓVOA, António. Os professores e as histórias da sua vida. In: NÓVOA, António. (Org.). Vidas de professores. 2. ed. Porto: Porto, 2000. p. 11-30.

ORGANIZAÇÃO DAS NAÇÕES UNIDAS PARA A EDUCAÇÃO, A CIÊNCIA E A CULTURA (UNESCO). Declaração mundial sobre educação superior no século XXI: visão e ação. Paris, 1998. Disponível em: <http://www. direitoshumanos.usp.br/index.php/Direito-a-Educa $\% \mathrm{C} 3 \%$ $\mathrm{A} 7 \% \mathrm{C} 3 \% \mathrm{~A} 3 \mathrm{o} /$ declaracao-mundial-sobre-educacao-superiorno-seculo-xxi-visao-e-acao.html>. Acesso em: nov. 2017.

PIMENTA, Selma Garrido; ANASTASIOU, Lea das Graças Camargo. Docência no ensino superior. São Paulo: Cortez, 2002

SANTOS, Betina Steren dos; ANTUNES, Denise Dalpiaz; SCHMITT, Rafael Eduardo. O processo motivacional na educação universitária. In: SANTOS, Bettina Steren dos; CARREÑO, Ángel Boza (Org.). A motivação em diferentes cenários. Porto Alegre, EDIPUCRS, 2010. p. 21-31.

SHÖN, Donald A. Formar professores como profissionais reflexivos. In: NÓVOA, António (Coord.). Os professores e sua formação. Lisboa: Dom Quixote, 1992. p. 77-91.

SHÖN, Donald A. Educando o profissional reflexivo, um novo design para o ensino e a aprendizagem. Porto Alegre: Artmed, 2000.

TRIVIÑOS, Augusto Nibaldo Silva. Introdução à pesquisa em Ciências Sociais: a pesquisa qualitativa em educação. São Paulo: Atlas, 2008.

YIN, Robert K. Estudo de caso: planejamento e métodos. 3. ed. Porto Alegre: Bookman, 2005.

Recebido em 04-01-2018 Aprovado em 12-03-2018. 